\title{
TIME, SPACE, AND THE INTERFACE OF DIVERGENT CULTURES: THE KAYAPÓ INDIANS OF THE AMAZON FACE THE FUTURE
}

\author{
Darrell A. Posey \\ (Center for Latin American Studies, University of Pittsburgh)
}

\section{INTRODUCTION}

The Brazilian Amazon captures much of the mystery of life, not only because of its vastness, complexity of plant and animal species and exotic indigenous peoples, but also because of its impenetrability (1). It is the last terrestrial frontier that defies modern technology and remains a challenge to the ingenuity of Western society. In the wake of sophisticated and enormous so-called "development" projects for the Amazon lies a lengthy chronology of ecological destruction. It is not just deforestation that has resulted, but irreversible "desertification" and related environmental degradation with which the world must now reckon (2). It has become obvious that there is little option but to re-evaluate the course of "progress" for the Amazon and look for alternative strategies as a basis for future development.

The Amazon has popularly been called a "Counterfeit Paradise" and a "Green Hell'. But to Indians, like the Northern Kayapó, it is "just plain home" and has been for millennia. Aboriginal Indian populations are now believed to have been quite dense, yet minimal environmental destruction resulted from their strategies of exploitation (3). It is in the cultures of the Kayapó and other surviving indigenous peoples that I propose we can find the secrets to new strategies for the reasonable development of the Amazon without the irrevocable destruction of its plants, animals and peoples.

The Kayapó Indians of southern Pará and northern Mato Grosso are one of Brazil's major indigenous groups (See Figure 1). The first permanent contact with the Kayapó was not until 1937 (4). Subsequently other Kayapó groups have been settled into villages with FUNAI (Fundação Nacional do Indio) post and medical services (5). The tribe remains, however, geographically remote and relatively unacculturated. The Kayapó have been fortunate in this respect, for their understanding of "civilizados" has been allowed to proceed slowly, without the sudden disruption of their ecological 
and cultural system (6). They remain today a proud people, who flourish because of an ecologically sound and diversified utilization of their Amazonian ecosystem (7).

Yet huge cattle ranche, plantations, and mineral developments are lapping at their very doorstep. The recent Cumarú gold rush and confusion over tribal boundaries has led to cultural conflict, deep resentment, and even bloodshed (8). There are plans for a road that woud cut through their reserva indigena and the westward frontier now gnaws at their tribal lands. Suddenly the Kayapó are face-to-face with the unrelenting tentacles of technology and society.

The purpose of this essay is to explore briefly the philosompical or world view of the Kayapò to reveal their sense of being in the world and how this world view affects their exploitation of the environment as well as the Kayapó are disadvantaged in dealing with Western society and technology. Ironically this patently practical matter must be dealt with at the most absract level of temporal and spatial concepts. I shall argue that it is the divergent notions of lineal vs. non-lineal time and space that the nature of "cultural interface" is revealed most clearly.

\section{ON TIME AND SPACE}

Time for Western civilization is refined to the point of having attributes of a substance or a commodity: we measure it, waste it consume it, treasure it. Space is inextricably correlated with time, for in our all-encompassing metaphysical plan, space is plotted on two transecting axes in a three dimensional expanse, the third dimension being formed by the lineal movemente of time (9). Time flows from past to present and extends into the future. This lineality allows us to pinpoint events in time and space, and to add the historical dimension upon which technological civilizations evaluate the present and predict the future.

Can any of us imagine not saving for the future, not planning ahead, not "making hay while the sun shines" Indeed, our cultural commitment to the lineality of time and space permeates the very fabric of our minds so that we cannot consciously imagine that life could exist without such constructs. Afterall, our biology, mathematics, physics and history have all validated the canonical laws of our scientific metaphysics. Sorokin pointed out the link between the development of mathematics and lineal time and the emergence of definite social developments connected with urbanization and industrialization (10). Few people, however, realize that science itself is a lineal, evolutionary product of classical Western philosophy and cultural traditions.

Benjamin Whorf, after studying the Hopi Indians, grasped the nature of a reality not built upon lineal constructs. He wrote: "Just as it is pos- 
sible to have any number of geometrics other than Euclidean which give an equally perfect account of space configurations, so it is possible to have descriptions of the universe, all equally, that do not contain our familiar constructs of time and space (11). Beidelman also mused that "we should no more be surprised at the alien or exotic features of primitive time reckoning than at the features of /ōther/ people's corresponding social organization or religious beliefs" (12).

The Kayapó recognize theree types of time, which can be called: 1 . ecological time, 2. structural time, and 3. macro-time (13). The first two types correspond to our own Western notions of time.

1. "Ecological time" corresponds to the natural yearly ecological and agricultural cycles. For the Kayapó, ecological time is divided into two seasons: the dry season, and the wet season. Further subdivisions are correlated with moon phases and stages of crop maturity (14).

2. "Structural time" is reckoned by human life cycles and is marked by periodic rites of passage. The Kayapó segment their population into six male age grandes and five female age grandes. Individuals pass from one age grande to another as they grow older and such changes are marked by specific ceremonies at more or less regular time intervals (15).

3. "Macro-time" brings us to the level of greatest abstraction and cultural divergence. It is at this abstract level that Kayapó notions of time and space drastically diverge from our own. To the Western mind, time is a precisely defined unit that can be measured in seconds, milli-seconds, or even micro-seconds. But at this level of abstraction for the Kayapó, neither time nor espace is measurable, or even definable. They become forces that are dynamic rather than kinematic i.e., erupting and emerging manifestations of dynamic energy with no definite direction or unified motion. The integrity of time and space disappears, or rather blends, into a motion that is without defined direction, yet eternal and omnipresent (16). I have labeled this realm of time and space as being maximally abstract, yet to the Kayapó this dimension is vibrant, scintillating, and shimmering with the mysterious energy of all that is life. This realm is at the very essence of all that was, is now, or will be Kayapó (17). Portions of this dynamic force are encapsulated as spirits of all living things. The Kayapó see themselves as an integral part of a world, whose natural components are all manifestations of the same energy. Not just people have spirits (karonn), but animals do as well, and plants act as balancing agents between these two spiritual realms. For this reason, the Kayapó have a profound respect for nature. Indeed, the health and well-being of individual and tribe is viewed as a proper "balance" between all natural forces (18).

The balance between the various encapsulated "spirits" of nature is symbolized by the circle. The universe is described in myths as being cir- 
cular, with floating parallel dises forming layers of the universe circumscribed by the greater outer circle (See Figure 2) (19). One of the parallel dises is the earth, which is likewise divided into concentric rings, the men's house (ngà) being the center of the circle, surrounded by the village, a transition zone, the forest and the outermost circle being the area of nonIndians (See Figure 3) (20). Kayapó villages, with their great circular rings of matrilateral extended households, (See Figure 4) are social manifestations of the circle (21). Hunting treks proceed in circular paths; hunting camps are arranged around circular sleeping and dancing areas. Kayapó fields are also circular niches carved out of the dense plant and animal realm of the jungle (22). Graves and graveyards are also circular (23). It has even been argued that the Kayapó social structure and kinship organization are circular in their organization (24). Thus the circle encompasses a definite reality and represents the cyclical essence of encapsulated units of time and space.

The principal natural manifestations of the circle are the sun and moon. The sun is circular and is believed to travel in a circular path across the earth, then up and around the sky layer above in order to reappear the next day (See Figure 2). The moon travels on the same path and the phases of the moon are images of the abstract forces that compose time and space, for the moon itself changes and even seems to disappear, but nonetheless remains the moon (25).

To the Kayapó, a human being is an illusion much like the moon. Each Kayapó has a human form or body (hĩ $k r a \tilde{a}-k a ̀)$, but the encapsulated energy that makes the body living is in the form of a circular ball (kadáwanh). The body only holds the spherical spirit, which is tenuously bound to its container. During periods of unconsciousness due to illness or injury, the spirit has a tendency to leave the body and wander about. While the spirit is outside the body, other spirits can invade the body or, if the spirit is lost, the body will die (26). Thus out-of-body experiences are risky and frightening to most Kayapó.

Shamans are called in during these periods of unconsciousness because they are experts on out-of-body experience. To become a shaman, in fact, the spirit must leave the body and pass through a severe illness (always characterized by "strong" fevers, kanêt tytx) and find its way to the spiritual realm that is the core of dynamic energy. The shaman's spirit learns many secrets abouts the nature of the relationship between the world of the living and the spiritual world. When the spirit of the shaman returns from its journey and re-enters the body, the shaman is reborn as a wise man who knows much about the universe (27).

Shamans are experts on tribal rituals and ceremonies because these communal events focus the activities of other Kayapó toward understanding 
the spiritual realm known to the shaman. Ceremonies become the link between the cyclical world of the Kayapó and the dynamic, timeless-spaceless spiritual realm.

The Kayapó have an elaborate and complex ceremonial repertoire. Ceremony is a raison d'être for the Kayapó, for they believe that without the performance of the prescribed rituals, the world would collapse: crops would not grow, children would not be born, the sun and moon would cease to travel across the sky.

Ceremonies are what maintain the balance of nature and are essential to generate the energy necessary to continue the ecological and structural time cycles. An important mechanism for producing this energy is through dancing, always accompanied singing. Men are the principal dancers and singers. They dance in pairs, following a circular path around the village plaza, or arm-in-arm swaying back and forth in circular or semi-circular lines. The dance steps are simple and the music monotonous and repetitive to the Western ear, yet harmonious and vaguely melodic (28).

Singing and dancing often begin at sundown and continue until sunrise, sometimes extending for seven or more consecutive nights (29). The combination of little sleep, and methodical, repetitious meter and tone of the music often leads participants into "elevated states of being" (consciousness). (30). It is during these elevated states that many Kayapó become awar of the non-lineal realm of dynamic power that unifies all time and space and links the cycles of ecolog.cal and structural time with the center of Kayapó non-lineal being (31). These experiences serve like a series of plugs that tap into a central power source to carry energy to the rituals, whose purpose is to insure the cyclical movement of time. This energy is transferred, or is manifest, symbolically through sexual intercouse. Intercourse is almost always associated with ceremonial activity, (32) and is often actually incorporated directly into the ritual itself (33). The Kayapó believe that strong children are born because of multiple sexual experiences. Even when pregnancy is well-advanced, intercourse continues to insure the growth of a healthy fetus (34).

Women say they rarely experience elevated states through dance or music, but do so during childbirth. This is highly symbolic since the altered state experience is a direct tie between the dynamic realm of being and the encapsulating birth event.

Death becomes nothing more than the return of a spirit to the dynamic realm. Birth and death, therefore, are really much the same since they merely represent structural transition between the cyclical world of the living Kayapó and the nonlineal dynamic realm of all being. It is little wonder that spirits of the dead are often encountered during ele- 
vated state experiences. The average Kayapó, however, is extremely frightened of such encounters. These spirits are potentially harmful since they can inhabit one's body permanently while one's own spirit is temporarily separated from the body during ritual dancing or illness (35).

Spirit forms are dealt with by shamans. Shamans have the ability to go into "deeper" or "stronger" elevated (or altered) (36) states of consciousness, and they are powerful enough to do so alone (i.e., without the necessary group rituals) and at any time they choose. They are able to manipulate the encapsulated human or animal spirits to cause or cure illness, talk to the spirits of the dead, or foretell the future. Shamans are the principal keepers of ritual knowledge and secrets: they are the specialists who know how to perform the essential rites that perpetuate the cycles of the Kayapó world. They manipulate the highly ordered rituals to induce elevated states and are embodiments of the relationships between lineally segmented cycles and the non-lineal realm of time and space.

What relationship does this esoteric topic have with the practical world of the Kayapó, i.e., how does the Kayapó view of time and space affect their chances for survival in the face of encroaching Western civilization?

Because of their belief in a timeless-spaceless, perpetual realm of dynamic force, the Kayapó appear to have little concern for the protracted future. They have little interest in "saving", "storing", or "guarding". They are greatly disadvantaged because of the lineal constructs of our mathematics and science, have no use for interpreting two-dimensional drawings, are puzzled by maps, find no reason to count past eight, and find no logic in earning wages or being punctual.

Since their ultimate concept of space is also one with no definite limits, they have conflicting notions of private space and do not adhere to basic Western tenets of individual land ownership. They do not operate with a concept of money, have no laws concerning land purchase, and find as alien the relationship between land boundaries and individual social rights.

More seriously, they do not understand the underlying concepts of development and progress that are so basic to the cultures they combat. They do not see themselves apart from the rest of the natural world, and, therefore, see no reason to develop strategies to subdue it. They are not on a lineal course through time and space that will, with the proper sacrifice and perseverence, make them masters over nature.

The Kayapó live in a circular, cyclical world, whose ideals are harmony and balance. Man, along with plants and animals, are manifestations 
of incapsulated units of the same energy. The world changes, but dynamically, not kinematically. All life is inextricably interrelated and exploitation by man of other life forms must not take place at the cost of the natural balance. This cyclical view is paradoxically the ultimate in long range ecological planning, for the Kayapó system operates to insure that there will be air, water, animals, trees and sources of energy for the future.

\section{CONCLUSION}

The interface between Western and Kayapó Indian cultures seems to be in the concept of "macrotime". This maximally abstract level of world view is expressed through divergent notions of time and space. Western technological society places high value on a metaphysical model that allows for a lineal progression of time from a definite past into a hypothetical, but manipulatable, future. Upon these basic principles rest the charter for the expansion of modern technology.

Expansion has proceeded in recent decades at incredibly rapid rates in places like the Brazilian Amazon due to an abundance of natural resources. This "progress" has occurred, however, at the expense of environmental stability and threatens the future of the Amazon, indigenous peoples like the Kayapó, and perhaps the ecological balance of the entire world.

The Kayapó see the processes of the universe and life as cyclical. Plants, animals and people are all manifestations of the same dynamic energy. The Kayapó strive for a harmony with other elements of the universe and sickness occurrs when the balance between man and nature is upset.

The overall balance between natural forces is maintained by performance of a complex cycle of rituals and ceremonies. These include singing and dancing and involve all Kayapó. Each individual, therefore, is directly involved in maintaining the harmony of life and is an agent in the perpetuation of ecological stability and the well-being of self and society.

Higher levels of abstraction for the Kayapó are in the spiritual world rather than in planning for a lineal future. The shamans are the intellectual leaders and are the ritual specialists specifically concerned with orchestrating the maintanence of balance in the cyclical Kayapó world. Thus Kayapó leaders are not chartered to direct the exploitation of natural resources, but rather to manage and maintain them.

The Kayapó world view is ultimately a model for long range ecological planning since it is based upon the preservation of species and natural resources. Indigenous systems of ecology, like that of the Kayapó, 
have evolved through millenia of adaptation and experimentation and form a valuable human resource. The study of folk ecological systems (which I call "folk ecology") offers important sources of information about the Amazon and long range strategies for human survival.

\section{EPILOGUE}

As Western technological society begins to face the world-wide shortage of natural resources, it is being forced to redefine its own basic constructs of time and space. Mushrooming social problems, overpopulation and famine, scarcity of land, water, minerals, and even oxygen, leave little choice but to re-evaluate the social consequences of "progress", "development" and "expansion". The theories of Western ecology that emerged in the 1960's offered an intellectual basis for "a new balance" between man, his technology and nature. There is now a popularized thrust to re-establish man as an integral part of the natural world. Could it be that only now modern society is coming to grips with a natural reality that the Kayapó discovered millenia ago? The Kayapó may not be well adapted to survival in the short range future against encroaching Western civilization, but one can only wonder if what they do know about the universe is not central to the future long term survival of humanity.

The stakes are high, not only for the indigenous population that remain and are threatened with extinction, but for the whole of humanity. It seems inconceivable that we could loose forever the knowledge of the environment and working systems of ecology that are encompassed in each and every indigenous culture. Yet one-by-one these indigenous cultural and philosophical systems have disappeared until now, in the decade of the '80's, the world is left with but a precious handfull of indigenous peoples. The wisdom of millenia of acquired human experience in the Amazon is vanishing before the world's eyes, paradoxically at the very time when the future is at best dubious for now dominant Western technological society.

Brazil is fortunate in her endowment with this richness of natural and human resources. Hopefully the upcoming decades will provide an avenue of mutual respect such that indigenous peoples can interact with the national culture without the destruction of the former and to the benefit of the human struggle for survival.

\section{NOTAS}

(1) - The original version of this paper was presented at the American Society for Ethnohistory, Annual Meeting, Albany, New York, October, 1979, and was written while a Fellow at the Newberry, Chicago, Illinois. I would like to thank the Newberry Library, its staff, and other Fellows in residence at that time (1979-1980) for their support. 
The data collected for this paper were collected during 1977-78 in a Kayapó research project sponsored by two grants from the Wenner-Gren Foundation for Anthropological Rerearch. I would like to acknowledge the assistance given to me by the Museu Paraense "Emílio Goeldi" staff (Belém do Pará, Brazil) and various personnel of the Instituto Nacional de Pesquisas de Amazônia (Manaus, Amazonas). My great appreciation for the cooperation of the many personnel of the Fundação Nacional do Indio (FUNAI), the Conselho Nacional de Pesquisa ( $\mathrm{CNPq})$, and the Brazilian Air Force (FAB).

I would also like to thank the following individuais for-their valuable comments on various versions of this paper: Helen Hornbeck Tanner, Henry F. Dobyns, Dan Usner, Carmen Chavez McClendon, John Frechione, John Singleton, Jeffrey Golliher, Gina Holloman, Peter MacBeath, John Eddins, and Micky Stout.

(2) - The seriousness of deforestation and the irreversible effects of "desertification" are summarized in four major works: Erik Eckholm and Lester R. Brown, "Spreading Deserts: The Hands of Man." World Watch Paper No. 13 (Washington, D. C. ), 1977 R. J. A.; Goodland and H. S. Irwin, Amazon: Green Hell to Red Desert? (Amsternam: Elsevier Scientific Publishing Company), 1975; Tropical Deforestation, Proceeding of the U. S. Strategy Conference on Tropical Deforestation (U.S. State Department), 1978; and Tropical Deforestation, Hearing before the Sucommittee on International Organizations of the House Committee on Foreign Affairs Washington, D. C.), 1980.

(3) - Varying estimates now exist for aboriginal populations in the Americas. Recent scholars emphasize the gross underestimate of aboriginal peoples. See Henry F. Dobyns, "Estimating Aboriginal American Population: An Appraisal of Techniques with a New Hemispheric Estimate, "Current Anthropology, Vol.7 (1966), 395416; and William M. Denevan, "The Abordiginal Population of Amazonia." The Native Population of the Americas in 1402. (Madison: University of Wisconsin Press), 1976.

(4) - The initial contact with the Kayapó was effected by the Reverend Horace Banner of the Unevangelized Fields Mission after earlier disastrous attempts by the legendary "Three Freds." This early history is recorded in three books by Horace Banner: The Three Freds: Matryred Pioneers for Christ in Brazil (London: Marshall, Morgan and Scott, Ltd.), n.d.; Long Climb on the Xingu (London: Green and Co., Ltd), 1963; and The Three Freds and After (Belfast: Graham and Heslip, Ltd.), 1975.

(5) - The most complete summary of the various Northern Kayapó groups is found in Gustaaf Verswijver's, Enquète ethnographique chez les Kayapó-Mekrãngoti. Unpublished thesis, École des hautes études en sciences sociales, Paris, 1978.

(6) - A relatively recent summary of the Kayapó village of Gorotire can be found in an article by Darrell A. Posey, "Cisão dos Kayapó Não Impede Crescimento Populacional." Revista de Atualidade Indigena, III, No 6 (1979), 53-58.

(7) - The ecological "adjustments" by the Kayapó to the environments of the area were the subject of a thesis by Joan Bamberger, Environment and Cultural Classification: A Study of the Northern Cayapó. Unpublished dissertation (Harvard University), 1967. The Kayapó remain excellent managers of their ecosystems, while providing abundant food for a balanced diet. For details, see Darrell A. Posey, "Kayapó Controla Inseto com Uso Adequado do Ambiente," Revista de Atualidade Indigena, III, No 15 (1979), 50-57.

(8) - Recent Developments in the Kayapó's relations with the "outside" world are monitored by the Anthropological Resource Center and reported in their Bulletin. The recent bloodshed over land rights is reported in Bulletin 4, (January 5, 1980), 15-17. Also see Informe Amazônico, Ano 1, Número 1, September 1980.

(9) - Benjamin Whorf, "An American Model of the Universe," International Journal of American Linguistics 16 (1950), 67-72.

(10) - Merton Sorokin, Sociocultural Causality, Space, Time. (Durham, N. C.: Duke University), 1943. 
(11) - Whorf, op. cit., 58 .

(12) - T. O. Beidelman, "Kaguru Time Reckoning." Southwest Journal of Anthropology, 19, No 1 (1963), 9-20.

(13) - The first two types of time distinctions were originally noted by E. E. Evans-Pritchard, "Nuer Time Reckoning." Africa, 12 (1939), 189-216.

(14) - For a detailed discussion of the yearly ecological and agricultural cycles of the Kayapó, see Darrell A. Posey, Ethnoentomology of the Gorotire Kayapó of Central Brazil. Unpublished dissertation (University of Georgia), 1979

(15) - The important subject of age grades and cycles of initiation are discussed by Lux Vidal, Morte e Vida de uma Sociedade Indigena Brasileira (São Paulo: Universidade de São Paulo), 1977. Also see Chapter 3 of Simone Dreyfus, Les Kayapó du Nord, État de Pará-Brésil (Paris: Mouton and Co.), 1963. Joan Bamberger also presents an analysis of the age grade system in "Kayapó Age Grades: A Case of Political Development in Central Brazil?" a paper presented to the symposium "Age and Generation: Hierarchical Relations in Lowland South America" at the 75th Meeting of the American Anthropological Association, Washington, D. C., 1976.

(16) - Anton Lukesch refers to this dynamic quality as "metamorphosis" in Chapter 1, Mito e Vida dos Índios Caiapós (Sãa Paulo: Universidade de Sãa Paulo), 1976. Many Kayapó myths deal with the nature of transformed/transforming entities, including what Johannes Wilbert categorizes as myths in the genre of "origins" and "animal stories" in his edited volume Folk Literature of the Gê Indians (Los Angeles: UCLA Press), 1978.

(17) - The best expression of the nature of the dynamic energy that is central to life for the Kayapó is in their beliefs about shamans (wayanga). Shamans have experienced first-hand the spiritual realm that vibrates and shimmers with energies of all types represented by animal "spirits" (karõn). The wayanga can "talk" and "commune" with these energies and can even manipulate some of them to produce observable results in Kayapó society. Myths about Kayapó shamans can be found in Anton Lukesch, Mito e Vida dos Índios Caiapós (São Paulo: Universidade de São Paulo), 1976 , especially pages $215,233,236-241$. The important relationship between physical and spiritual transformation (or "metamorphosis" to use Lukesch's term) as embodied by the shaman is also reflected in myths recorded in Johannes Wilbert, Editor, Folk Literature of the Gê Indians (Los Angeles: UCLA Press), 1978, about "The man who turned into the rain" (p. 117), "The spirit man" (p. 123), "The man who made people" (p. 156), and "The talking animals" (p. 247) to name a few; also see Vidal (op. cit., 210-212). For a discussion of the "flight" of the shaman from his body through the dynamic realm of the spiritual world, see Darrell A. Posey, "The Journey to Become a Shaman: A Narrative of Sacred Transition of the Kayapó Indians of Brazil, "Journal of Latin American Indian Literatures (University of Pittsburgh), in press.

(18) - The best source of knowledge about the Kayapó concepts of plants and anmals is in their myths. In Anton Lukesch's book (op. cit.), see Chapter 6, for myths describing the relationship between humans and animals, and Chapter 7, for human-plant relationships. On pages 77-80, Lukesch also discursses the ancient notions of balance and harmony that permeate Kayapó thought.

(19) - See Lukesch (op. cit., 9-23) and Wilbert (op. cit., 29-30, 95-111) for myths about the origin and nature of the universe.

(20) - The description of the Kayapó "earth layer" as a series of concentric circles is suggested by Del Snyder of the Unevangelized Fields Mission in a manuscript entitled "Introdução da Língua Kayapó" (Araguacema, Goiás), 1964. Terence Turner utilized the same model in his thesis Social Structure and Political Organization among the Northern Cayapó (Harvard University), 1965, Chapter 2. Also see the concentric circle diagramatic of Kayapó world view in Joan Bamberger, Environment and Cultural Classification: A Study of the Northern Kayapó (Harvard University), 1967, p. 124. 
(21) - The circular theme of the Kayapó and other Gê groups as reflected in the spatial arrangement of villages is discussed in Lux Vidal (op. cit., Chapter 2) and is the central theme of Roberto da Matta's Um Mundo Dividido (Petrópolis: Editora Vozes), 1976.

(22) - See Vidal (op. cit., 77-80). The ideal field for the Kayapó is a circular one of about 0.6 acres. Contact with "civilisados" has altered the shape and size of Kayapó fields. See Bamberger, op cit., 108-117; also see Darrell A. Posey, "Kayapó Controla Inseto com Uso Adequado do Ambiente," Revista de Atualidade Indigena,
III, No 15 (1975), 50-57.

(23) - Micky Stout comfirms (private correspondence) that the Kayapó see their round graves in symbolic opposition to the square graves of the Brazilian.

(24) - This idea is presented in great detail by Terence Turner in his dissertation Social Structure and Political Organization among the Northern Cayapó (Harvard University), 1965, Chapter 5; pay special attention to Figure 7. Turner, in a more recent work, "Kinship, Household, and Community Structure among the Kayapó, "in Dialectical Societies: The Gêe and Bororo of Central Brazil, David Maybury-Lewis, Editor (Cambridge, Mass.: Harvard University Press), 1979, discusses what he calls the "balance" of the kinship structure and social organization to form a structure of "bilateral symmetry" (See especially pages 180, 181, 190).

(25) - There are many myths about the sun and moon. For some of the most important Kayapó myths, see Wilbert (op. cit., 32-74).

(26) - The myth, "O Xamã e a Morte" is a symbolic representation of the nature of death. See Vidal (op. cit., 210-211).

(27) - The spirit "flight" associated with becoming a shaman and its relationship with fevers is discussed in some detail by Darrell A. Posey in "The Journey to Become a Shaman: A narrative of Sacred Transition of the Kayapó Indians of Brazil, "Journal of Latin American Indian Literatures (University of Pittsburgh), in press.

(28) - For a description of Kayapó music, see Chapter 5 of Simone Dreyfus, Les Kayapó du Nord, Etat de Para-Brésil (Paris: Mouton and Co.), 1963.

(29) - The elaborate and complex nature of one of the most famous of Kayapó ceremonies (Bemp) is described in Chapter 4, Section 4, of Terence Turner's dissertation (op. cit., 167-245).

(30) - The term "elevated state" is used ambiguously in anthropological literature. There is considerable research on the subject, for which a good introduction is E. Hillgard's Divided Consciousness (New York Wiley-Interscience), 1977. Suffice it to say that there are various "levels" of elevated states of consciousness. The elevated state described here is one bordering on extreme euphoria or mesmerization. Dancing and singing do not generally induce "deep" states, but rather the loss of specific temporal and spatial orientations. This "state" is not unlike what can be effected by modern rock concerts and similar "intense" or "heavy" experiences. The rituals associated with dancing and singing often, but not always, produce elevated states of consciousness for male participants. Not all participants experience elevated states at every ritual every time any more than every Catholic has a "religious experience" at every mass. As Jeffrey Golliher points out in "Attending Mass: The Viewpoints of Two Ritual Participants" (unpublished paper given at the Conference on Culture and Communication, Temple University, Philadelphia, 1981), Catholics attend mass for a variety of social, political, and religious reasons. The idealized goal, however, is to achieve a "sacred state", just as the idealized goal for the Kayapó is to experience the "dynamic realm" through their rituals.

(31) - I do not wish to imply that all dancing and singing ceremonies have as their sole purpose the induction of "elevated states." This is definitely not the case for the bulk of Kayapó singing and dancing, which can be labelled as simply recreational. For ceremonies that are prolonged and associated with important events in the ecological and structural time cycles, however, "elevated states" become a mark of the seriousness with which the Kayapó view the dancing and singing associated with the event. 
(32) - The actual temporal connection between ceremonial activities and the birth rate in the Kayapó village of Gorotire is charted in Darrell A. Posey's "Cisão dos Kayapó Não Impede Crescimento Populacional." Revista de Atualidade Indígena, III, No. 16 (1979), 53-58.

(33) - Terence Turner describes in his dessertation the importance of ceremonial sexual intercourse in the Bemp and Mê-i-tykre ceremoines. See Chapter 4, Section 4, Part 4 of Social Structure and Political Organization Among the Northern Cayapó (Harvard University, 1965), pp. 219-248.

(34) - Joan Bamberger discusses in her dissertation the relationship between sexual intercourse and fetus health and development (op. cit., 163). Also see Chapter 3 of Simone Dreyfus (op. cit.).

(35) - See Lukesch (op. cit., 206-214) for a brief discussion of human ghosts (mê-karõn) .

(36) - Whereas dancing and singing for the average Kayapó leads to "slight", elevated states of consciousness, the Kayapó shaman (wayanga) can go into "deep" trance states. The ability to effect such a trance is part of the knowledge attained from the spirit "flight" previously described. Shamanistic trance states are induced through fasting, chanting and smoking (tobacco or genipapo leaves). 


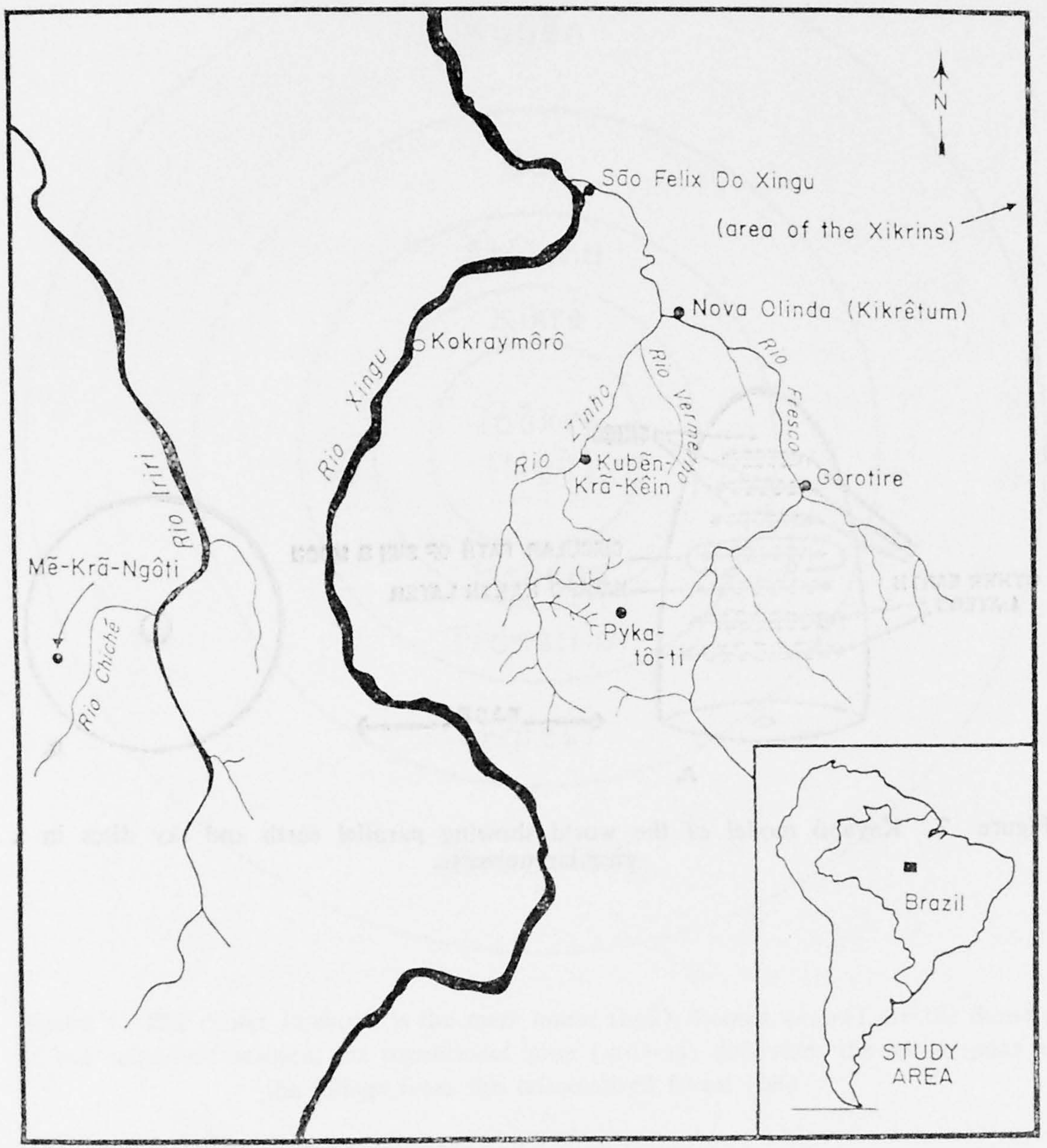

Figure 1. General Geographic Orientation of the Kayapo Indian Villages of Central Brazil. 


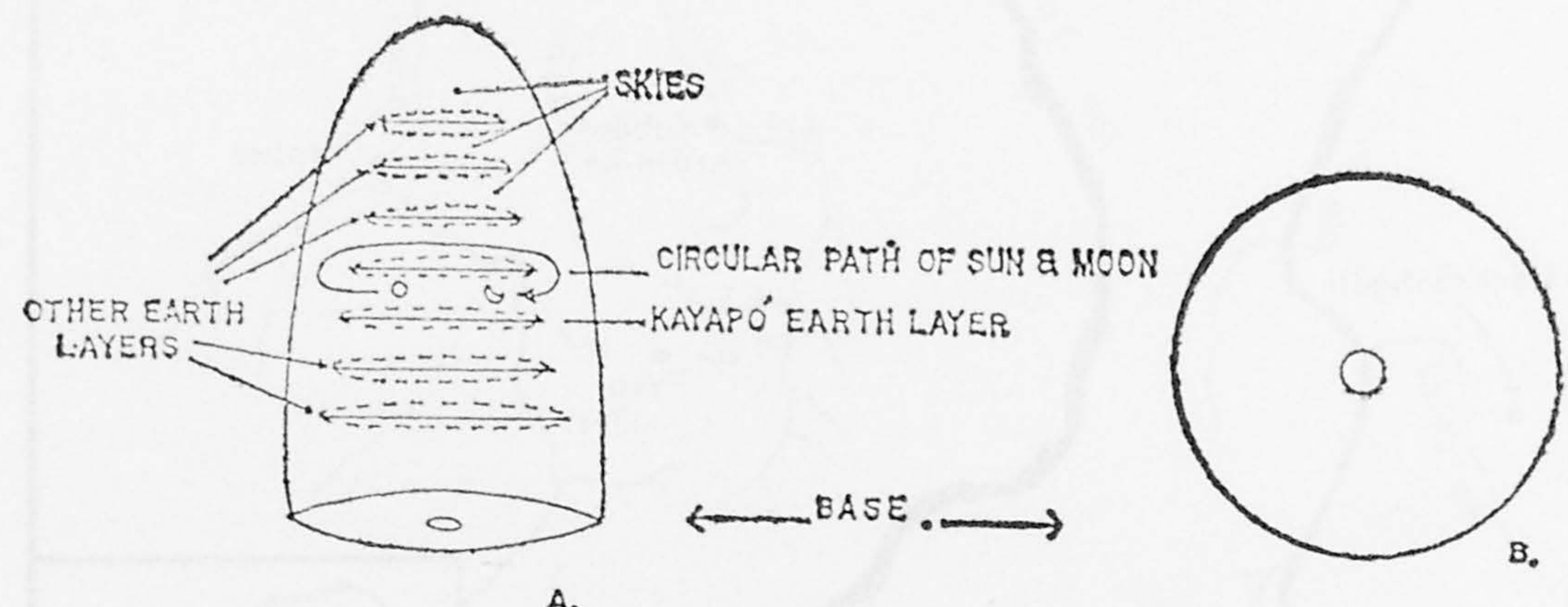

A。

Figure 2. Kayapó model of the world showing parallel earth and sky discs in a circular universe. 


\section{SPACIAL MODEL OF THE KAYAPÓ WORLD}

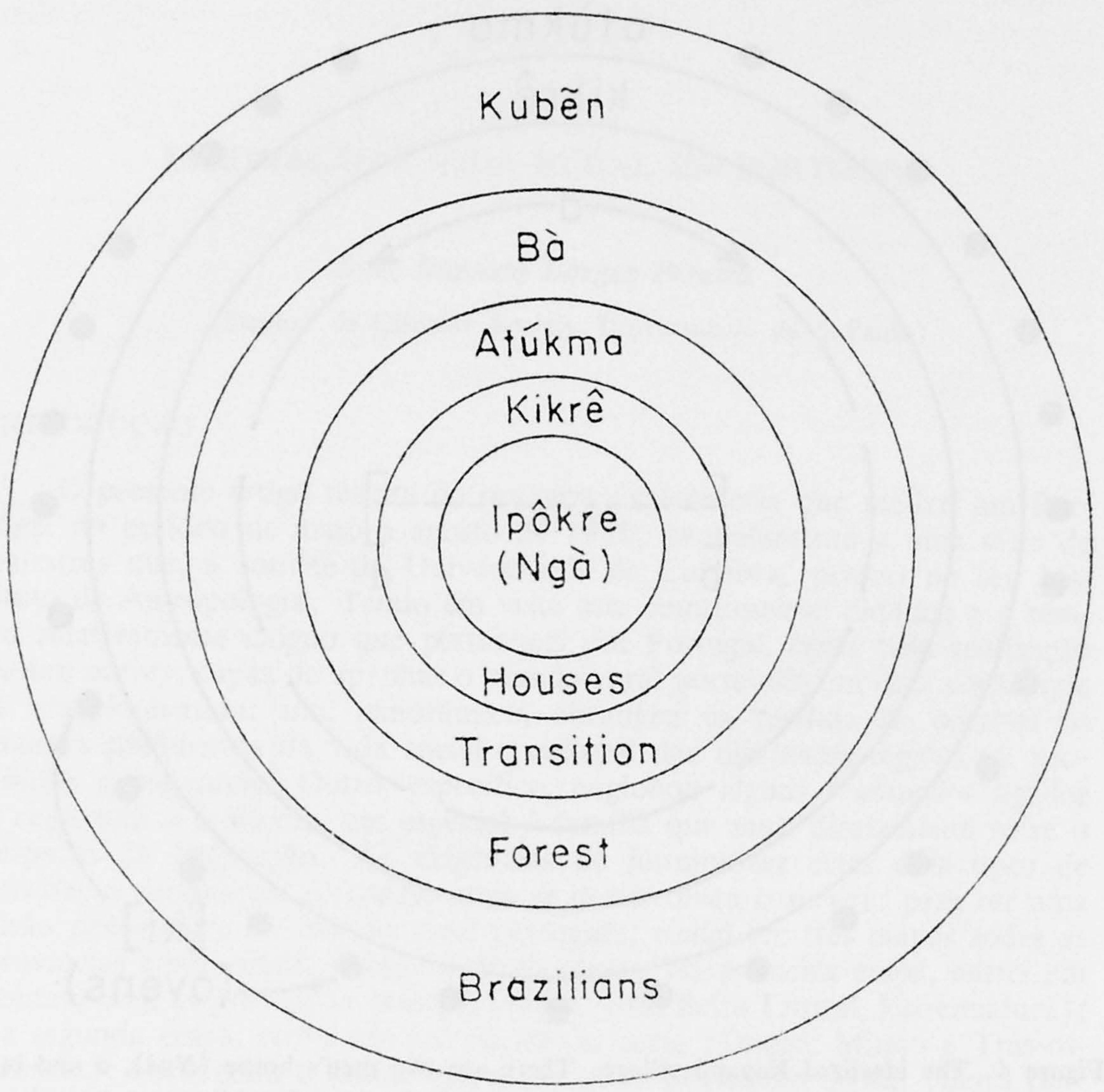

Figure 3. The center (ipôkre) is the men' house (ngà); houses (kikrê) are the domain of less socialized women; the transitional zone (atukma) delineates the social space of the village from the unsocialized forest (bá). 


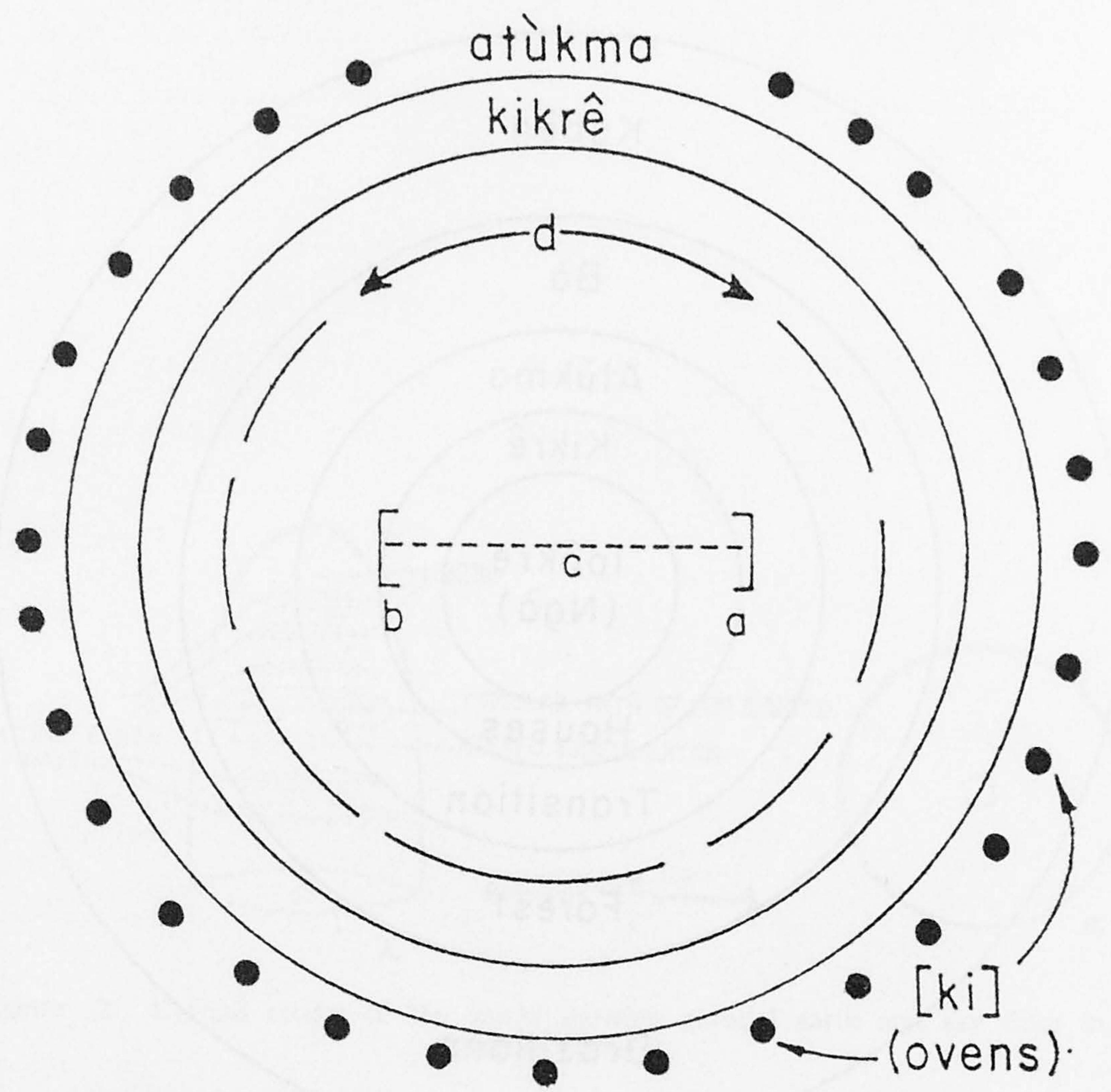

Figure 4. The idealized Kayapó village. There are two men's house (Ngà), a and b, eastern (kratx) and western (nhôt), connected by "the Path of Chiefs" (c). A "dancing circle" is (d).

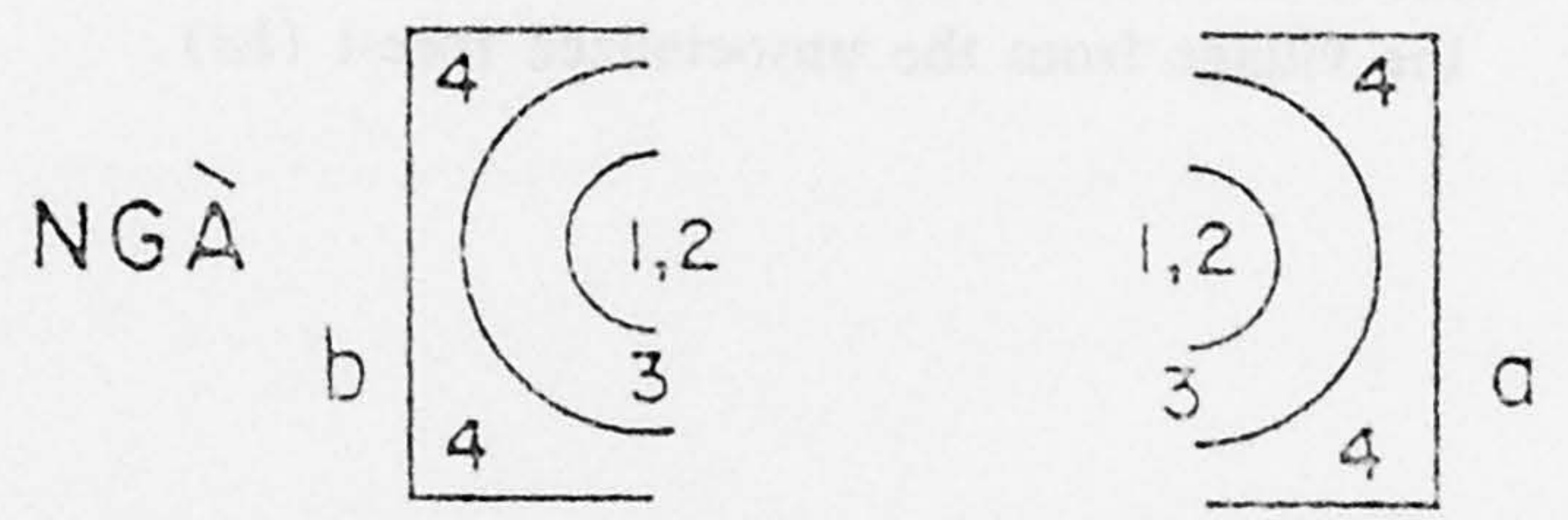

Sitting places in the Men's house are represented obove. (I) mê-ôkre,

(2) mê-nõnõnure, (3) mê-krare, and (4) mê--benget. 